\title{
THE SCALE-ADUSTED LATENT CLASS MODEL: APPLICATION TO MUSEUM VISITATION
}

\author{
PAUL F. BURKE,* CHRISTINE BURTON,* TWAN HUYBERS, † TOWHIDUL ISLAM, \\ JORDAN J. LOUVIERE,* and CHELSEA WISE*
}

*University of Technology, Sydney, Australia

tUniversity of New South Wales, Australia

‡University of Guelph, Canada

Preferences of tourists and visitors are varied in a number of markets, making it difficult for managers to understand how underlying segments might respond to changes in service offerings. Market segments differ in preferences for specific features, as well as how consistently they make their choices. In this article, we illustrate recent developments in choice modeling that allows for simultaneously modeling feature preferences and consistency of choice. We use the Scale-Adjusted Latent Class Model (SALCM) to better understand choices in the context of a research project conducted in collaboration with six major Australian museums involving a sample of $3,685 \mathrm{mu}$ seum visitors. We identify three preference classes of museum-goers that explain preferences for levels of 26 museum attributes: Life Force (two thirds of visitors), Educated Thinkers, and Wealthy At-Homes. Our results indicate sensitivity to general entry prices, including preference for free entry or entry "by donation." Tours are preferred if smaller, lengthier, and conducted by paid museum staff. Not unexpectedly, the findings suggest that museums should cater for children, with some classes responding positively to providing supervised child areas. Most visitors prefer museums that are dynamic, offer new experiences, and regularly update permanent displays. However, the three classes identified have different overall experience preferences; for example, Educated Thinkers see museums as an educational opportunity, but Wealthy At-Homes prefer entertaining experiences. Incentives for return visits and cross-museum promotional offers are valued by the Life Force class, but have little effect on Educated Thinkers. The SALCM approach may be attractive to other areas of tourism analysis, especially where offerings contain many attributes and potential market segments are difficult to define and understand.

Key words: Museum visitation; Discrete choice experiments; Latent class models; Heterogeneity; Segmentation

Introduction

Museums are often a "must-see" attraction for domestic and international tourists visiting a destination region, city, or town. By visiting museums, tourists often acquire a better appreciation of what defines the destination across widespread dimensions like transportation, industry, technology, war, art, and literature. Among local residents, museums can provide places of remembrance, celebra-

Address correspondence to Dr. Twan Huybers, Senior Lecturer, School of Business, University of New South Wales, Australian Defence Force Academy, Canberra ACT 2600, Australia. Tel: +61 26268 8075; Fax; +61 2 6268 8450; Email: t.huybers@ adfa.edu.au 
tion, or even escape. In general, motivations to visit museums vary, but largely relate to enhancing knowledge and social interactions that include entertaining distractions (Burton, Louviere, \& Young, 2008; Slater, 2007). In turn, museums compete with other offerings that appeal to similar motives, such as cinemas, theaters, home entertainment, eating out, or attending sporting events (Johnson \& Thomas, 1998). Such diverse competition makes attracting visitors difficult and museums have been criticized for their inability to do so (Burton et al., 2008). Arguably, such difficulties might be expected when one considers museums' historical role as largely not-for-profit organizations that increasingly are expected to compete against "for-profit" organizations. Strategic reconsiderations for museums have evolved out of decreases in government subsidies (Lee, 2005) and private philanthropic sponsors (Burton, 2003). Thus, museums increasingly understand that attracting visitors requires them to deliver products that are valued by individual customers (Holden, 2003; Weil, 2002).

Addressing museum visitation matters from both macro- and microeconomic viewpoints. Museums can be seen as attractions for visitors external to a destination, providing economic implications for other spatially proximate organizations like tourism operators and hotels (Throsby, 2001). From a cultural viewpoint, the presence of museums in communities gives a sense of pride and identity that act as memorials to the past and signal a sense of confidence in a region's future. At a microlevel, museums can reconfigure their offering in many ways, including changes to tangible aspects of their products (e.g., exhibitions, food, merchandise) and intangible service aspects (e.g., staff knowledge, type of tours, interactivity). Museum managers have limited resources to reconfigure offerings, so they would benefit from innovative methods that allow them to understand what visitors value, such that reconfigurations are strategically informed as accurately as possible in advance.

Thus, the purpose of this article is to apply a Scale-Adjusted Latent Class Model (SALCM) to address the question of what is valued by museum visitors. Our research focuses on what constitutes value at a microlevel in terms of attributes or features of museums that are directly under the con- trol of individual museums, such as opening hours and pricing. To do so, we consider microeconomic models of consumption choice, conceptualizing the decision to visit a particular museum as being preceded by a series of trade-offs among tangible and intangible characteristics of museums' offerings and the premium consumers are willing to pay in terms of prices, times, and effort to obtain these. We view existing valuation methods as measuring value in absolute rather than relative terms. In contrast, we propose and apply discrete choice experiments (DCEs) as a way to derive new insights by measuring offerings in terms of the relative value that visitors place on attributes/ features that combine to create an overall museum experience.

To achieve our wider research objectives, we build on recent advances in discrete choice modeling to account for differences in preference and choice variability among museum visitors. While many advances have been made to understand differences in how segments value one feature relative to another (i.e., preference), accounting for differences in choice variability has been more elusive. Choice variability refers to how inconsistent individuals are in their overall choices; and individuals may be more or less variable/consistent due to several reasons, including uncertainty or confusion. Choice variability is related to the stochastic (random) component and, as such, reflects any nondeterministic behavior from the viewpoint of researchers. In other words, individuals typically do not always choose what appears to be their most preferred alternative and instead choose alternatives that seem to be less than optimal. Our focus is on groups or segments of choosers, and these groups can be viewed as being more or less consistent in their choices relative to one another.

Differences in choice variability are rarely taken into account in empirical choice modeling work, but failure to do so can lead to serious bias and incorrect conclusions (Louviere, 2001). Choice variability is inversely related to the parameters of choice models that one estimates, and so it plays a major role in the quality and interpretation of the estimates one derives from choice experiments or other types of choice data. For example, one may conclude that a segment holds very different pref- 
erences to another, but the differences may simply be the result of differences in how consistent the choices are that reveals the preferences in each segment (Louviere, 2001). We take both choice variability and preference into account by estimating a relatively new model, the Scale-Adjusted Latent Class Model (SALCM) proposed by Magidson and Vermunt (2005). The SALCM identifies latent (unobservable) segments that simultaneously differ in two ways: 1) in preferences for a given attribute/feature and its levels, and 2) in the variability with which overall choices are made. Previous applications of latent class models did not take choice variability differences into account, characterizing the latent segments (classes) only in terms of preference differences. As far as we are aware, this is the first application of this model in tourism research.

\section{A Choice Model of Museum Visitation}

Traditionally, marketers assert that successful product differentiation can be achieved by offering consumers something relatively important and valuable that stands out from what others offer $(\mathrm{Ca}$ hill, 1996). The value that consumers derive from products (including services and experiences) depends on the underlying characteristics or attributes (Lancaster, 1966) of the services, such as museums. Value to museum visitors can be associated with attributes like guided tours, exhibited artifacts, and interactive displays. Visitor choices involve trade-offs whereby they give up one attribute or attribute level to obtain another (Louviere, 1988). In the case of museums, potential visitors may visit a museum with interactive exhibits even if it has a high entry price. Visitors may consider many attributes in making decisions, or they may consider only a few; hence, managers often lack clear understanding of the relative importance of product attributes. Museums face constraints due to costs, policies, supply issues, and sustainable economic practices, and try to maximize the attributes of their "offerings" to provide an "ideal" museum experience (Sheth, Newman, \& Gross, 1991). Hence, museum managers need to understand the trade-offs that visitors will make for attributes that can be changed. For example, a museum could consider extending opening hours to attract visitors, but if potential visitors place more value on staff knowledge of exhibitions, it may be better to allocate resources to staff training than extending opening hours.

Museum managers have been keen observers of their markets over the past decade. Many use qualitative methods such as focus groups, in-depth interviews, and observational techniques. For example, Bitgood (2006) uses a general value principle (i.e., cost vs. benefits) to account for the trade-offs that visitors use in moving around an exhibition. On a more sensory level, Joy and Sherry (2003) use observation and in-depth interviews to determine visitors' visceral and embodied imaginative responses to exhibitions. Thyne (2000) uses content analysis of interviews and a laddering technique to determine factors that influence museum visitation, but did not report how influential they were. While these and similar studies (e.g., Debenedetti, 2003; Goulding, 2000; Wiggins, 2004) identified many potential factors that might affect museum experiences, they did not isolate or measure key attributes that influence museum visitation decisions. In addition, in the absence of wellconceived external validity tests, there are validity issues noted by Biehal and Chakravarti (1989).

Museum managers extensively use survey research to learn about visitors. For example, surveys are used to try to measure the "importance" of various factors in visitation decisions. The methodologies employed include ranking, constant sum, and rating scales, to compare institutions on demographics, visitation frequency, satisfaction, and summative evaluation of exhibitions (Kirchberg, 1996). Similar to the validity issues noted above with qualitative methods, ranking and constant sum scales can be difficult for respondents when they have to rank or allocate points across many factors (Cohen \& Orme, 2004). Single-item rating scales can be problematic when respondents rate many (or even all) factors as important. As every feature is treated equally, there is no real disincentive to choose as noted by Carson and Groves (2007). Compounding this are issues related to differences in individuals' use of such scales. For example one person's three may be the same as another's four or vice versa. And, of course, it is widely recognized that rating scale re- 
sponses are influenced by cultural norms (e.g., Hui \& Triandis, 1989).

Other quantitative research methods that have been used to study cultural heritage include Kelly's (2004) Repertory Grid Analysis and Contingent Valuation. Kelly's grid has been used to identify the strength of museum brands (Caldwell \& Coshall, 2003) by proposing that people make choices based on analogous associations. While repertory grid analysis allows individuals to direct the way in which associations are determined, it does not allow one to make predictions about choices. Anticipating museum visitation choices requires one to take into account interest, tastes, and motives, not typically observed in repertory grid analysis.

Contingent valuation (CV) (Mitchell \& Carson, 1989) has been used to measure the economic value of cultural resources (e.g., Noonan, 2003; Santagata \& Signorello, 2000). CV methods typically ask respondents about their willingness to pay for a well-defined and described option, such as a particular museum exhibition, although there is nothing inherent in the $\mathrm{CV}$ approach that excludes variation in product features. Our research approach has many features in common with $\mathrm{CV}$ approaches, but is more general than typical $\mathrm{CV}$ applications because we design and implement a discrete choice experiment (DCE) that allows us to analyze survey responses with discrete choice models that can be used to predict likely visitor choices.

The qualitative and quantitative research reviewed above suggests that visitors may use several attributes of museums to value museum attractiveness. These include social factors, identity development, and consumption experiences (Falk, 2006), and artistic/aesthetic, emotional, and educational factors (Boorsma, 2006). Differences in the attributes that visitors evaluate and care about may be associated with psychographic factors, differences in visitor segments, and/or other leisure consumption differences (Clopton, Stoddard, \& Dave, 2006). As noted by Cohen and Neira (2003), all too often when consumers are asked to evaluate potential attributes of products or services like museums, they rate all or many attributes as equally important, providing little discrimination among attributes and less useful strategic insight than meets the eye. Thus, managers of museums and other tourism service suppliers could benefit from research methods that provide sharper and better discrimination between potential attributes.

Louviere and Islam (2008) have compared four different ways of measuring importance weights, two direct (i.e., rating scales and best-worst scaling) and two indirect methods (i.e., discrete choice experiments and implied willingness to pay measures). Direct approaches measure the importance of a set of attributes by asking respondents to state the degree of importance or weight on some category rating or constant sum scales. Indirect approaches generally try to elicit importance by analyzing an outcome measure like choices. They found different results from direct and indirect preference elicitation approaches. According to Louviere and Islam (2008), indirect measures provide richer insights about trade-offs among attributes and provides more meaningful managerial inputs due its natural link with consumer purchasing context. Jaccard, Brinberg, and Lee (1986) also found lack of convergence among direct and indirect measures of importance. In absence of underlying theoretical reasons for such differences, we use indirect measures that have external validity in the literature (see Louviere \& Islam, 2008, for discussion on external validity of indirect measures).

\section{Discrete Choice Experiments and Tourism Research}

While it is safe to assume that various attributes/levels drive museum visitation decisions, it is unclear which ones singly or in combination matter most (Kelly, 2004) or to whom. Discrete choice experiments (DCEs) and associated discrete choice models (DCMs) offer a potential way to quantify what drives museum visitor choices (Burton, 2003; Burton \& Scott, 2003). In the research reported below, DCMs are used to analyze the outcomes of a DCE in which past or potential visitors were asked to make choices in a series of choice sets. The sets were constructed to systematically vary a number of attributes of museums that can be changed. The sets were based on prior qualitative research that identified a range of ele- 
ments that matter when choosing a museum visit. DCEs are widely used to represent everyday choices, such as products on shelves in supermarkets, transport mode options for commuting, and recreational offerings like parks or fishing locations (e.g., Louviere, Hensher, \& Swait, 2000). Choice response data from DCE surveys can be analyzed with choice models to uncover systematic relationships between choices (dependent variable) and changes in product/service offerings or "attributes" (independent variables).

The choice modeling literature is now fairly mature, and comprehensive reviews can be found in Train (2003) or Louviere et al. (2000). More recently, it has been recognized that more complex models are required that can take differences in individual choice variability into account (e.g., Adamowicz et al., 2008; Islam, Louviere, \& Burke, 2007; Louviere \& Swait, 2010). Thus, we make use of relatively new developments in finite mixture models, known as latent class models. We take advantage of a new type of latent class model known as a "scale-adjusted latent class model" that can simultaneously account for differences in choice variability and preferences (Magidson \& Vermunt, 2005).

Use of DCMs in tourism and leisure research has grown in line with software developments and applications in other fields. Applications of choice models in tourism have typically focused on modeling tourism demand (e.g., Huybers \& Bennett, 2000; Morley, 1994). DCMs have also been applied to other topics such as resident trade-offs of tourism impacts (Lindberg, Dellaert, \& Rassing, 1999) and understanding decisions relating to leisure experiences, (Oh, Ditton, Gentner, \& Riechers, 2005; Ready, Epp, \& Delavan, 2005; Verma, Louviere, \& Burke, 2006). This literature demonstrates the flexibility of DCMs beyond traditional consumption decisions. There have been fewer applications of DCMs to cultural heritage research. Boxall, Englin, and Adamowicz (2003) and Rolfe and Windle (2003) used DCMs to value aboriginal artifacts in Canada and Australia, respectively. Maddison and Foster (2003) used DCEs to study museum congestion. Apostolakis and Jaffry (2005) and Mazzanti (2003) applied DCMs to museums in Greece and Italy, respectively, to understand museum demand.

\section{Accounting for Individual Differences in Preference and Variability}

One of the key advantages in using DCMs revolves around modeling decisions to visit museums and how these decisions may be affected by changes to museum features. Early DCMs, such as McFadden's (1974) conditional logit model, restrict the preferences of individuals to be homogeneous; hence, preferences estimated in these models are sample averages. In turn, this raises aggregation bias concerns (Hutchinson, Kamakura, \& Lynch, 2000); for example; when all females prefer museums with longer opening hours, but all males are indifferent. In such a case, one would underestimate the effects of extended opening hours on choices of both genders if they are equally represented in a sample.

One way to account for such preference differences (or heterogeneity) is to include interactions between observable covariate measures (e.g., demographics, psychographics) and product features in DCMs (Gupta \& Chintagunta, 1994). Auger, Burke, Devinney, and Louviere (2003) report significant individual differences in valuation of ethical product features related to several demographic measures. In other cases, some of the heterogeneity in preferences may be unrelated to observable covariate measures, but, instead, be latent. Several methods have been proposed to deal with this, including random coefficient models (e.g., Hierarchical Bayes and Mixed Logit models) and finite mixture models (Kamakura \& Russell, 1989; Wedel \& Kamakura 1998; for a recent review of models in this area, see Train, 2003). These methods differ in several ways, including whether the heterogeneity is modeled using several discrete classes (as we do) or is continuous (i.e., using a distribution, as in the case of models like the mixed logit) (see Andrews, Ainslie, \& Currim, 2002). In addition, there are notable differences in how researchers conceptualize and identify heterogeneity with some using a priori theory-based model development approaches, while others use 
a data-driven approach where segments are identified in a posterior fashion (Dolnicar, 2004).

Of course preference differences are not the only potential source of differences in individual choices. Individuals also may differ in choice consistency. For example, younger visitors may be less certain about how much they will enjoy a particular special exhibition or which particular exhibition they prefer due to less overall experience with museums. Failure to account for differences in choice variability can lead to biased and misleading conclusions about preferences. This is because each person's mean preference parameter estimates are inversely related to their choice consistency (Louviere, 2001). Yatchew and Griliches (1985) showed that error variance or heteroscedasticity ignored by researchers in a choice model (discussed in the context of a probit model) will result in biased parameter estimates rather than simple loss of efficiency as in the case of a linear model. Mroz and Zayats (2008) cautioned interpreting coefficient estimates of binary outcomes from different samples even if they use identical estimation procedure as these estimates depend crucially on arbitrary normalization of variance. Virtually all random coefficient models assume that choice consistency is constant across individuals, but if it is not constant, estimates of such models can be highly biased. Recent work by Fiebig, Keane, Louviere, and Wasi (in press) and Salisbury and Feinberg (2010) suggest that it is highly unlikely that choice consistency is constant across individuals.

Addressing the potential confound between model estimates and choice consistency, several new types of DCMs have been developed to account for unobservable error variance heterogeneity such as the Generalized Multinomial Logit model (Fiebig et al., in press), models for single persons (Louviere et al., 2008), models that decompose the random component (Burke \& Reitzig, 2007), and scale-adjusted latent class models (Magidson \& Vermunt, 2005). Fiebig et al. (in press) have shown unobserved scale heterogeneity models outperform models that only account for taste heterogeneity such as MNL and mixed logit in 10 out of 10 data sets. Accordingly, unobserved scale heterogeneity was more important in datasets that involve more complex choice objects.
Differences in preferences for museums were reported by Apostolakis and Jaffry (2005) and Mazzanti (2003), who estimated interactions between observable respondent characteristics and museum attributes. Colombino and Nese (2009) used a mixed logit model to account for unobservable preference heterogeneity, but did not allow for differences in choice consistency. Thus, prior work suggests differences in choices of museum visitors, but does not pinpoint likely or potential sources of heterogeneity.

Our research makes a methodological contribution to the museum demand literature by using a recent development in latent class estimation that allows preference parameters to differ for discrete, but unobserved (latent) classes of people, while also allowing the underlying variability of the random errors to differ between several discrete latent classes. Until recently, latent class models allowed preferences to differ from class to class, but the error variances were identical over classes. Error variance unaccountability confounds true underlying preference variability with individual differences. This means that apparently significant differences in preference parameters between latent classes may be due to differences in underlying scale (Louviere, 2001).

Magidson and Vermunt (2005) developed a way to deal with the error variance-parameter estimate confound, embedding the new approach in commercially available software (a beta version of Latent GOLD). The estimation approach allows one to relax the restriction that the scale parameter is fixed across the whole population, effectively decomposing class preferences and scale (or error variability). It also allows latent preference and scale classes to be described as functions of demographic and other covariates. We now discuss prior work on DCMs, after which we introduce and highlight the advantages of the SALCM.

\section{Choice Models Derived \\ From Random Utility Theory}

Using the conceptual framework of Random Utility Theory (Manski, 1977; Thurstone, 1927), each individual may be described as holding latent preferences (utilities) associated with all choice options being considered. Individuals maximize 
utility by choosing their most preferred option. Latent preferences are specified by two components (observed and unobserved). Different discrete choice models are derived from different assumptions about the unobserved component, the best known of which is the conditional multinomial logit model or MNL (McFadden, 1974). MNL assumes the unobserved component is independently and identically distributed across choices and individuals. In this model, the latent utility of option $i$, judged by respondent $n$, is given by: $U_{n i}=\beta^{\prime} X_{n i}+$ $\varepsilon_{n i}$, where $X_{n i}$ is the vector of attributes of option $i$, and $\beta$ is a vector of parameters representing the preference (i.e., weight) associated with each attribute. By assuming $\varepsilon_{n i}$ to be i.i.d. extreme value type I, McFadden showed that the choice probability from a total of $J$ options considered is given by:

$$
P_{n i}=\frac{\exp \left(\beta^{\prime} X_{n i}\right)}{\sum_{j=1}^{J} \exp \left(\beta^{\prime} X_{n j}\right)}
$$

It is important to recognize that the MNL, model parameters in equation (1), $\beta_{\mathrm{MNL}}$, are not the true underlying $\beta$ in $U_{n i}$. As is the case for all choice models, the estimates are confounded with $\sigma_{\varepsilon}$, the standard deviation of the error distribution (Swait \& Louviere, 1993; Train, 2003). Thus, one actually estimates $\beta^{*}=\lambda \beta$, where $\lambda$ is commonly referred to as "the scale parameter" and in the case of MNL, the relationship is $\lambda=\pi /\left[\operatorname{sqrt}(6) \sigma_{\varepsilon}\right]$.

To avoid confounding preference estimates with choice consistency, we use the SALCM to estimate relative scale parameters jointly with preference classes and associated preference parameters. Indeed, without estimating $\lambda$ (i.e., restricting $\lambda=1$ for all classes), even in finite mixture models where one allows the preference parameters $\beta^{*}$ to vary between latent classes of consumers, it is still possible to misinterpret differences in the true underlying $\beta$ between classes which may be due only to differences in $\lambda$ (Louviere, 2001).

\section{Scale-Adjusted Latent Class Models (SALCM)}

Magidson and Vermunt (2007) proposed a model in which the random utility of option $j$ for individual $n$ depends on the latent preference class $q=1 \ldots Q$ and the unobserved scale parameter class $\lambda_{d}, d=1 \ldots D$, and each individual is expressed in terms of the likelihood that they belong to each class. For identification, one scale parameter is normalized to unity (see Swait \& Louviere, 1993); the remaining scale parameter estimates are ratios of the reference scale class. The probability of choice $i$ by individual $n$ in choice situation $t$, conditioning on preference class $q$ and scale factor class $d$ is:

$$
P(n t i \mid q, d)=\frac{\exp \left(\lambda_{d} \mid \beta_{q}^{*^{\prime}} x_{n, i}\right)}{\sum_{j} \exp \left(\lambda_{d} \beta_{q}^{*^{\prime}} x_{n, j}\right)}
$$

We assume that there are $Q$ discrete latent classes and $D$ scale groupings, but that class membership is hidden. However, we allow for the classes to be determined using a set of observable characteristics or demographics. If $H_{n q \mid d}$ is the prior probability for preference class $q$ for individual $n$, and $G_{n \mid d}$ is the prior probability for scale group $d$, the multinomial logit model suggested by Hensher and Greene (2002) can be used to estimate each prior as:

$$
\begin{aligned}
& H_{n q \mid d}=\frac{\exp \left(\theta_{q}^{\prime} z_{n}\right)}{\sum_{q} \exp \left(\theta_{q}^{\prime} z_{n}\right)} \\
& G_{n \mid d}=\frac{\exp \left(\gamma_{q}^{\prime} z_{n}\right)}{\sum_{d} \exp \left(\gamma_{q}^{\prime} z_{n}\right)}
\end{aligned}
$$

where the vector $z_{i}$ includes $k=1 \ldots K$ relevant covariates or sociodemographic characteristics of individual $n$ including a constant, and $\theta$ and $\gamma$ are the respective vectors of parameter estimates of those $z_{i}$ covariates. In turn, the overall $\log$ likelihood is:

$$
\ln L=\sum_{n=1}^{N} P_{n}=\ln \left[\sum_{d=1}^{D} \sum_{q=1}^{Q} G_{n \mid d} H_{n q \mid d} \prod_{f=1}^{T} P_{n i \mid q, d}\right]
$$

We followed the recommended estimation procedure in Latent GOLD and used 20 randomized sets of starting values to ensure an identified global maximum. We choose the number of preference and scale classes by comparing the Bayesian Information Criterion (BIC) associated with 
each class solution, which rewards improved fit and penalizes additional parameters. The posterior probability that an individual belongs to preference class $q$ and scale class $d$ can be inferred from Bayes' theorem.

\section{Discrete Choice Experiment Survey}

We now describe a DCE that provides choice data that can take advantage of the SALCM by decomposing choices into preference and scale components, and allows both to vary across the underlying latent segments. The main objective of the DCE and associated survey was to quantify the effects of tactical and strategic museum attributes in order to better align museum offerings, tactics, and strategies with visitor choices. We first describe research that preceded the DCE undertaken to enhance external validity and provide strategic information to the six collaborating museums. It is arguably the case that the most important stage in a DCE is the prior identification of salient attributes and levels as the accuracy and validity of a DCE depends entirely on it. Additionally, one must balance the number of attributes identified against the size and scope of the resulting choice tasks; for example, including many factors leads to large DCEs and more complex tasks that have implications for sample costs, task complexity, report delivery, and presentation complexity. Yet, omission of salient attributes may lead to model misspecification and omitted variable bias, as well as concerns about external validity.

As previously noted, we used qualitative interviews with museum visitors (Burton et al., 2008) to identify a long list of potentially salient attributes for visitors and potential visitors. We then conducted another round of research to measure the saliency of 64 attributes using a Best-Worst Scaling approach (Marley \& Louviere, 2005). We used the results of the Best-Worst Scaling exercise to discuss which of the attributes in fact could be changed with representatives from partner museums. This resulted in a final 26 attributes; and discussions with our museum partners allowed us to specify a relevant set of levels for each attribute.

The final list of 26 attributes and associated levels are in Table 5 . There were 2 eight-level attributes, 9 four-level attributes, and 15 two-level attributes. The collection of all possible combinations of these attributes comprises $8^{2} \times 4^{9} \times 2^{15}=$ $3,774,873,600$ combinations. We used Street and Burgess' (2007) design theory to construct an efficient set of 128 pairs that were blocked into eight choice sets per respondent. This design approach is based on an orthogonal main effects plan (OMEP) that allows estimation of a main effects only model.

The DCE was embedded in a larger online survey that focused on questions about leisure activities and museum visitation. The first part of the survey asked respondents about whether they had engaged in various leisure activities in the previous year, and whether they expected to do so in the next 12 months. Visiting a museum, whether past or prospective, defined eligibility as a participant in the study, and the study context was revealed to qualifying respondents. The second part of the survey consisted of two museum exhibition tasks. In the first task, respondents were asked to indicate if they would or would not go to see each of 37 named (and described) exhibitions. The second task focused on a subset of 9 of the 37 exhibitions; respondents were asked to rate each on a five-category rating scale ranging from very unattractive (one star) to very attractive (five stars). Each subject was randomly assigned to a different set of nine exhibitions based on a balanced incomplete block design. The latter design consists of 37 blocks of 9 exhibitions; each exhibition appears 9 times across the 37 sets (blocks), and co-appears with each other exhibition twice.

In the third section of the survey, the DCE, respondents received instructions and an example of a DCE scenario that explained how to answer the questions. Following that, they received eight scenarios or choice sets (see Fig. 1). Each attribute was described in a "pop-up box" displayed when the cursor was held above that feature. Respondents were instructed to consider star ratings of "special exhibitions" as representing their own attractiveness ratings exemplified by their responses to the prior exhibition rating task. Respondents were asked to indicate their preferred museum offer and whether they would actually visit that museum for each choice set. The survey concluded with questions about preferred days for extended opening hours and respondent sociodemographic 


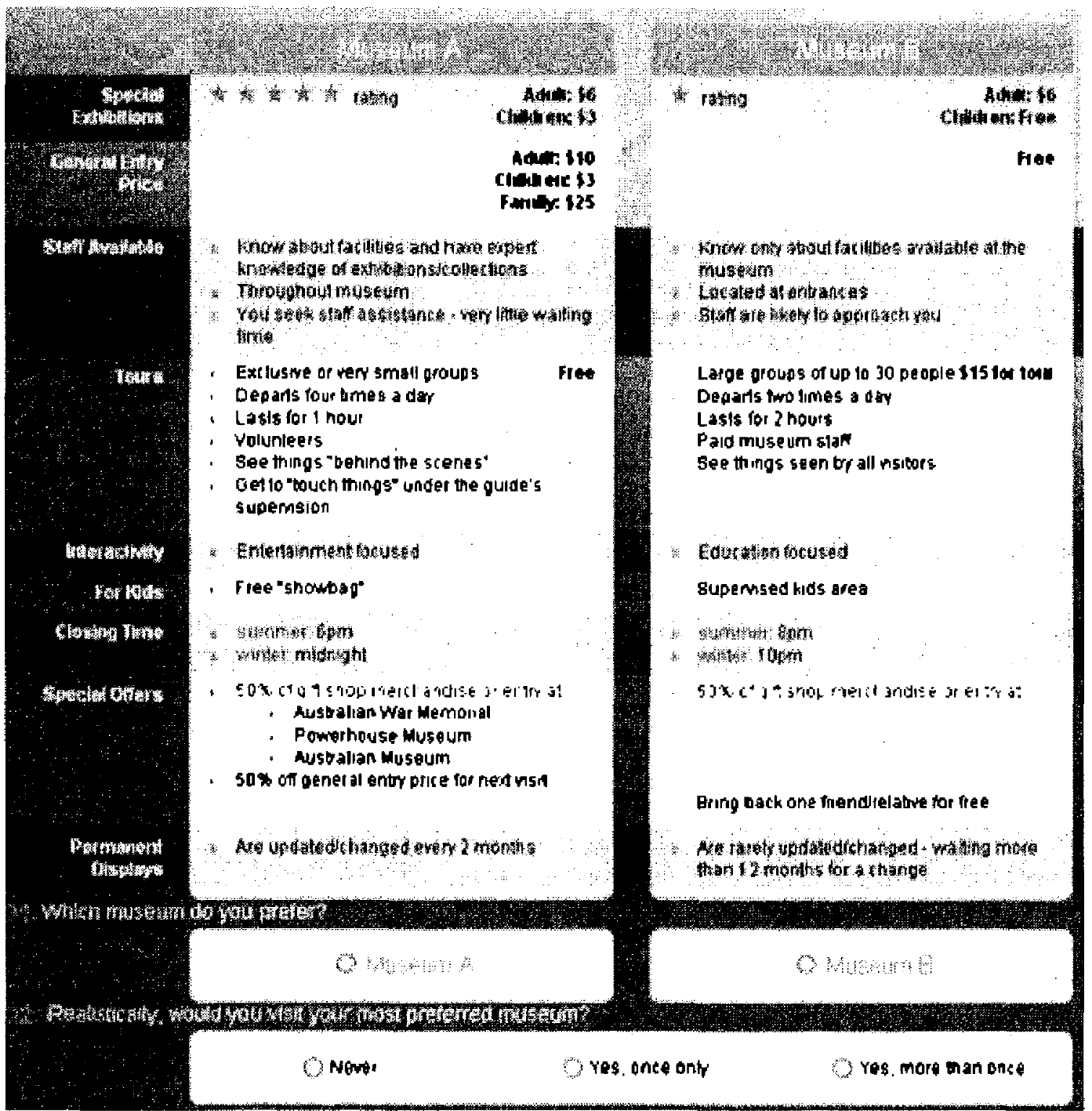

Figure 1. Example choice set.

characteristics consistent with Census Bureau questions.

Survey responses were collected over 3 months (beginning June 2007) using PureProfile, an online panel providing access to a sampling frame broadly representative of the Australian population. Visiting a museum (the screening criterion for the survey) was ranked 12 th in the past activities list and fifth in the intended activities list. There were $64.3 \%$ of respondents who had visited a museum in the last year and $89.2 \%$ of respondents reported that they intended to visit one in the next year. After accounting for incomplete re- sponses and withdrawals, the final sample for this study consisted of 3,685 respondents. Table 1 displays the sociodemographic characteristics of the sample.

\section{Results}

We fitted a SALCM using sociodemographics, types of activities engaged in by individuals, and rated preferences for different real exhibitions to capture preference heterogeneity (i.e., latent classes) and variance heterogeneity (i.e., scale classes). We iteratively estimated a number of models to ensure 
Table 1

Sociodemographic Profile of Respondents

\begin{tabular}{|c|c|}
\hline Characteristic & $\%$ \\
\hline \multicolumn{2}{|l|}{ Age in years } \\
\hline $18-24$ & 13.4 \\
\hline $25-29$ & 11.6 \\
\hline $30-34$ & 10.7 \\
\hline $35-39$ & 12.0 \\
\hline $40-45$ & 13.4 \\
\hline $46-49$ & 7.5 \\
\hline $50-55$ & 11.5 \\
\hline $56-59$ & 5.5 \\
\hline $60-65$ & 9.4 \\
\hline $66-69$ & 2.8 \\
\hline $70+$ & 2.0 \\
\hline \multicolumn{2}{|l|}{ Hosehold income } \\
\hline$\$ 20,000$ or less & 5.7 \\
\hline$\$ 20,001-\$ 30,000$ & 6.1 \\
\hline$\$ 30,001-\$ 40,000$ & 6.9 \\
\hline$\$ 40,001-\$ 50,000$ & 8.8 \\
\hline$\$ 50,001-\$ 60,000$ & 8.8 \\
\hline$\$ 60,001-\$ 70,000$ & 8.0 \\
\hline$\$ 70,001-\$ 80,000$ & 8.9 \\
\hline$\$ 80,001-\$ 90,000$ & 7.4 \\
\hline$\$ 90,001-\$ 100,000$ & 8.9 \\
\hline$\$ 100,000+$ & 30.4 \\
\hline \multicolumn{2}{|l|}{ Household } \\
\hline Single, living alone & 14.2 \\
\hline Single, living in a shared house & 10.4 \\
\hline Single, living with children & 5.1 \\
\hline Single, living with parents & 9.1 \\
\hline Married/de facto with no children & 20.5 \\
\hline Married/de facto with children & 28.7 \\
\hline Married/de facto, children left home & 12.0 \\
\hline \multicolumn{2}{|l|}{ Education } \\
\hline Primary school & 0.7 \\
\hline High school & 19.0 \\
\hline TAFE/college/diploma & 30.2 \\
\hline Undergraduate degree & 30.5 \\
\hline Postgraduate degree & 19.6 \\
\hline \multicolumn{2}{|l|}{ State/territory } \\
\hline Australian Capital Territory & 1.9 \\
\hline New South Wales & 33.6 \\
\hline Northem Territory & 0.5 \\
\hline Queensland & 19.1 \\
\hline South Australia & 7.8 \\
\hline Tasmania & 1.7 \\
\hline Victoria & 26.0 \\
\hline Western Australia & 9.4 \\
\hline \multicolumn{2}{|l|}{ Area } \\
\hline Metropolitan & 78.8 \\
\hline Rural/regional & 19.5 \\
\hline
\end{tabular}

that we had reliable estimates of the number of classes and final model specification. The final model (three preference classes) was selected on the basis of minimizing $\mathrm{BIC}=-2 \mathrm{~L}+m \log (n)$, where $L$ is the model log-likelihood with $m$ parameters and $n$ observations. The corresponding
BICs are 40888.6 (one class), 39710.9 (two class), 38288 (three class), and 38453.4 (four class).

The BIC indicated two scale groupings, with $\lambda_{1}=1$ (by normalization; see Swait \& Louviere, 1993) and $\lambda_{2}=0.186$; implying that the second class shows 5.4 times $(1 / 0.186)$ more variability in underlying responses than the first group. Variance heterogeneity is explained by age $(\gamma=0.0810$; $p=0.0175$ ), indicating that younger people were more variable in their museum visitation choices than older people. Of the total DCE participants, $73 \%$ and $27 \%$ were most likely to be members of scale class one and two, respectively.

To minimize multicollinearity between measures of activities engaged in during the past year and stated interest in various museum exhibitions, we specified the SALCM using constructs informed by the results of a factor analysis. That is, we used principal components analysis with Varimax rotation, retaining components with eigenvalues larger than 1 to derive a more parsimonious set of covariates. This produced seven activityrelated factors (Table 2) and seven exhibitionrelated factors (Table 3 ). We labeled factors by considering exhibitions or activities with the highest factor loadings and identifying a consistent theme. In both cases, the seven factors explain about $60 \%$ of the variance in the data.

We estimated the preference classes using the multinomial logit model of equation (3) and retained three latent classes using the BIC criterion. The vector of covariates $z_{i}$ consisted of age, household income, education, and the 14 rotated factor scores discussed previously. Table 4 shows the characteristics that predict membership of the three resulting preference classes.

The largest visitor segment $(61 \%$ of the sample) is distinguished from other segments by being more likely to be lower to middle in income, with a basic education and no tertiary qualifications. They prefer activities associated with betting and gambling, are less likely to prefer self-expressive activities (e.g., playing music and writing), and are attracted to exhibitions with themes related to fashion and romance. Museum managers who sponsored the research confirm that such people comprise most of their museum visitors. By sheer weight of numbers, these people represent the Life Force that flows through museums. 
Table 2

Factor Analysis: Interest in Exhibitions

\begin{tabular}{|c|c|}
\hline Factor & Exhibitions Loading Onto Factor \\
\hline $\begin{array}{l}\text { Australia Since } \\
\text { British Settlement }\end{array}$ & $\begin{array}{l}\text { Australian Joumeys: How people traveled to Australia over time and traveled back; The River: Life } \\
\text { on the Murray-Darling; Great railway journeys of Australia; Surviving Australia: Celebrating the } \\
\text { unique, diverse and surprising aspects; Your City's History: The social, cultural and physical charac- } \\
\text { ter of your city over time }\end{array}$ \\
\hline Wartime & $\begin{array}{l}\text { Great wartime inventions; Lucky escapes: Untold stories of wartime escapes; In Flanders Fields 1917: } \\
\text { Fighting around Ypres in WWI; Lawrence of Arabia and the Light Horse: Objects and artifacts }\end{array}$ \\
\hline Animals & $\begin{array}{l}\text { Bugs Alive: Up close to live spiders and insects; Jellyfish: Beautiful, awe inspiring and dangerous to } \\
\text { know; Marine life: Exploring our seas-deep sea to shallow waters }\end{array}$ \\
\hline Ancient Worlds & $\begin{array}{l}\text { Ancient civilizations: Civilizations including Egypt, Greece, and China; Gladiators: Combining ar- } \\
\text { chaeology, popular culture and forensic science; Dinosaurs of Gondwana Discoveries in Australia, } \\
\text { Antarctica, and South America }\end{array}$ \\
\hline $\begin{array}{l}\text { Fashion and } \\
\text { Romance }\end{array}$ & $\begin{array}{l}\text { Tiffany Bejeweled: A collection of superbly crafted jewelry and accessories; Diana: An exhibition } \\
\text { celebrating the life of H.R.H Princess Diana; Love and war: Pinups, sweethearts, boyfriends, \& love } \\
\text { letters during the war }\end{array}$ \\
\hline The Modern Mind & $\begin{array}{l}\text { Drugs \& culture: The use and (mis)use of drugs across cultures; The Mind: Exploring the workings } \\
\text { of the human mind and our emotions; Modem Times: Celebrates "modernism" }\end{array}$ \\
\hline Indigenous Cultures & $\begin{array}{l}\text { Deeds: Large Aboriginal canvases of the Papunya art movement of the 1970s; Vaka Moana: Voyages } \\
\text { of the ancestors: exhibition of Maori seafaring and culture }\end{array}$ \\
\hline
\end{tabular}

The smallest of the three visitor groups has advanced education qualifications and enjoy selfexpressive pursuits. They are less likely to engage in activities relating to betting, gaming, or home entertainment. They avoid fashion and romantically themed exhibitions, but prefer indigenous culture and Australian history. This group of Educated Thinkers comprises $14 \%$ of the sample.

The third visitor group (comprising a quarter of respondents) were labeled as Wealthy At-Homes. They have higher incomes, and engage in activities at home including helping children with homework and computer use. They show little interest in Australian-themed exhibitions. They completed high school, but are less likely to hold trade or diploma qualifications than the other groups.

The SALCM allows us to quantify preferences for museum features for each underlying class in the sample, conditional on variance and preference heterogeneity. These results are in Table 5, which is structured to reflect the attribute groupings in the survey (Fig. 1). Significant results are denoted by two symbols: the first $\left(^{*}\right)$ denotes whether a factor is significantly different from zero (i.e., $\beta \neq$ 0 ), and therefore significant in explaining choice within a class; the second $(\dagger)$ denotes whether a factor is significantly different (i.e., $\beta_{q} \neq \beta_{i}$ ) from the preferences exhibited by the Life Force segment.

Table 3

Factor Analysis: Activities Engaged in Over Previous Year

\begin{tabular}{ll}
\hline Factor & \multicolumn{1}{c}{ Activities Loading Onto Factor } \\
\hline Self-expressive & studying; writing; playing musical instruments \\
Passive Arts & theater/cultural events; visiting art gallery; gourmet food and wine \\
Do-it-Yourself & home renovations/improvements; gardening; vehicle maintenance \\
Gambling & gambling/betting \\
Games (with children) & board games/puzzles; helping children with homework; computer games \\
Grandchildren & spending time with grandchildren \\
Exercise & personal exercise; participation in organized sports \\
\hline
\end{tabular}


Table 4

Multinomial Logit Estimation of Preference Class Characteristics

\begin{tabular}{lccc}
\hline Covariate & $\begin{array}{c}1: \text { Life Force } \\
(61 \% \text { of Sample })\end{array}$ & $\begin{array}{c}\text { 2: Educated Thinkers } \\
(14 \% \text { of Sample) }\end{array}$ & $\begin{array}{c}\text { 3: Wealthy At-Homes } \\
\text { (25\% of Sample) }\end{array}$ \\
\hline Intercept & $0.973(0.106)^{* * *}$ & $-0.700(0.143)^{* * *}$ & $-0.273(0.102)^{* * *}$ \\
Age & $-0.015(0.039)$ & $-0.077(0.052)$ & $-0.062(0.039)$ \\
Quadratic & $-0.006(0.024)$ & $-0.052(0.029)^{*}$ & $-0.046(0.024)^{*}$ \\
Income & $-0.021(0.017)$ & $0.000(0.000)$ & $0.021(0.017)$ \\
Quadratic & $-0.013(0.005)^{* *}$ & $-0.005(0.007)$ & $0.018(0.006)^{* * *}$ \\
High school & $0.175(0.090)^{*}$ & $-0.367(0.138)^{* * *}$ & $0.191(0.094)^{* *}$ \\
TAFE/college/diploma & $0.181(0.070)^{* * *}$ & $-0.145(0.101)$ & $-0.036(0.078)$ \\
Undergraduate degree & $-0.066(0.068)$ & $0.214(0.090)^{* * *}$ & $-0.148(0.074)^{* *}$ \\
Postgraduate degree & $-0.290(0.079)^{* * *}$ & $0.298(0.096)^{* * *}$ & $-0.008(0.081)$ \\
Activitics & & & \\
Self-expressive & $-0.178(0.045)^{* * *}$ & $0.253(0.060)^{* * *}$ & $-0.076(0.047)$ \\
Passive arts & $-0.014(0.043)$ & $-0.064(0.056)$ & $0.078(0.045)^{*}$ \\
Do-it-Yourself & $-0.001(0.048)$ & $0.082(0.054)$ & $-0.082(0.042)^{*}$ \\
Garnbling & $0.098(0.043)^{* *}$ & $-0.123(0.056)^{* *}$ & $0.025(0.043)$ \\
Games (with children) & $0.008(0.040)$ & $-0.158(0.054)^{* * *}$ & $0.149(0.043)^{* * *}$ \\
Grandchildren & $0.025(0.045)$ & $0.040(0.058)$ & $-0.066(0.049)$ \\
Exercise & $-0.012(0.042)$ & $-0.035(0.058)$ & $0.047(0.044)$ \\
Exhibitions & & & \\
Australia Since British Settlement & $0.028(0.043)$ & $0.102(0.059)^{*}$ & $-0.130(0.045)^{* * *}$ \\
Wartime & $-0.009(0.039)$ & $0.016(0.052)$ & $-0.007(0.045)$ \\
Animals & $0.040(0.040)$ & $-0.050(0.056)$ & $0.009(0.042)$ \\
Ancient Worlds & $-0.010(0.045)$ & $0.075(0.057)$ & $-0.066(0.042)$ \\
Fashion and Romance & $0.247(0.044)^{* * *}$ & $-0.324(0.063)^{* * *}$ & $0.077(0.046)^{*}$ \\
The Modern Mind & $0.023(0.042)$ & $-0.053(0.057)$ & $0.029(0.043)$ \\
Indigenous Cultures & $-0.057(0.040)$ & $0.092(0.053)^{* *}$ & $-0.034(0.042)$ \\
\hline
\end{tabular}

Values are estimated $\beta$ with SE in parentheses.

Coefficient significant at: ${ }^{*} 0.1, * * 0.05$, and $* * * 0.01$ level.

\section{Special Exhibitions}

Special exhibitions were described by a one- to five-star rating (five is "not to be missed") and corresponded to respondents' own attractiveness rating in the prior exhibition rating task in the survey. Across all segments, attractiveness of special exhibitions is significant in explaining museum visitation choices (Table 5a). However, there are differences in each segment. For example, for the Life Force class, a highly rated exhibition is more likely to produce visits from higher educated persons, but the opposite occurs for Educated Thinkers. Highly rated exhibitions have a large impact on visitation choices in the Wealthy At-Homes class. Thus, managing themes of exhibitions should be carefully considered for all classes, especially Wealthy At-Homes, who have little interest in exhibitions like "Australia Since British Settlement."
However, the importance of highly rated exhibitions is less important among older visitors.

Special Exhibitions were also described with an extra entrance fee. The Life Force class prefers exhibitions that are free or by donation; preferences linearly decline with increases in the adult entry price. Both other classes also prefer free special exhibitions and entry by donation, and this effect is significantly larger than for Life Force. There is greater sensitivity among Wealthy At-Homes and Educated Thinkers to entrance charges. Despite being labeled as Wealthy At-Homes, results suggest a high level of price sensitivity, which may be because family museum visits can be expensive in relation to a family's disposable income.

\section{General Entry Price}

The pattern of results in relation to general entry prices is similar to special exhibition prices, 
Table 5

Attributes and Associated Levels

\begin{tabular}{|c|c|c|c|}
\hline & $\begin{array}{l}\text { Class 1: } \\
\text { Life Force }\end{array}$ & $\begin{array}{l}\text { Class 2: } \\
\text { Educated Thinkers }\end{array}$ & $\begin{array}{l}\text { Class 3: } \\
\text { Wealthy At-Homes }\end{array}$ \\
\hline \multicolumn{4}{|l|}{ a. Special Exhibitions } \\
\hline \multicolumn{4}{|l|}{ Star rating } \\
\hline Intercept (aggregate) & $0.232(0.026)^{* * *}$ & $0.307(0.112)^{* * *}$ & $1.791(0.193)^{* * * \dagger \dagger \dagger}$ \\
\hline$\times$ Age (linear) & $-0.018(0.010)^{*}$ & $-0.041(0.041)$ & $-0.022(0.030)$ \\
\hline ×Age (quadratic) & $-0.012(0.007)^{*}$ & $-0.036(0.028)$ & $-0.055(0.019)^{* * * \div \dagger}$ \\
\hline xIncome (linear) & $-0.004(0.005)$ & $0.005(0.019)$ & $-0.006(0.015)$ \\
\hline xIncome (quadratic) & $-0.003(0.002)^{*}$ & $0.002(0.007)$ & $-0.009(0.006)$ \\
\hline$\times$ Gender (male) & $0.031(0.013)^{* *}$ & $-0.004(0.049)$ & $0.003(0.045)$ \\
\hline xEducation (high school) & $-0.028(0.025)$ & $-0.074(0.078)$ & $0.023(0.070)$ \\
\hline xEducation (college) & $-0.048(0.020)^{* *}$ & $0.118(0.079) \dagger \dagger$ & $-0.059(0.069)$ \\
\hline$\times$ Education (undergraduate) ${ }^{\circ}$ & $0.009(0.023)$ & $0.131(0.074)^{*}$ & $-0.009(0.070)$ \\
\hline xEducation (postgraduate) & $0.066(0.031)^{* *}$ & $-0.175(0.080)^{* *++\dagger}$ & $0.044(0.077)$ \\
\hline \multicolumn{4}{|l|}{ Price } \\
\hline Free & $0.214(0.066)^{* * *}$ & $0.745(0.245)^{* * *+1+1}$ & $1.063(0.246)^{* * *+\dagger \dagger}$ \\
\hline Free, donation appreciated & $0.306(0.062)^{* * *}$ & $0.759(0.218)^{* * *+\dagger \dagger}$ & $1.411(0.268)^{* * *+\dagger \dagger}$ \\
\hline Adult: $\$ 6$, children: Free & $0.025(0.060)$ & $0.346(0.213)$ & $0.355(0.221)$ \\
\hline Adult: $\$ 6$, children: $\$ 3$ & $-0.010(0.061)$ & $-0.020(0.247)$ & $-0.333(0.217)$ \\
\hline Adult: $\$ 6$, children: $\$ 3$, family: $\$ 15$ & $-0.057(0.062)$ & $-0.369(0.229)$ & $-0.105(0.255)$ \\
\hline Adult: $\$ 10$, children: Free & $-0.171(0.064) * *:$ & $-0.614(0.211)^{* * *+\dagger}$ & $-0.590(0.256)^{* * *}$ \\
\hline Adult: $\$ 10$, children: $\$ 3$ & $-0.197(0.062) * *$ & $-0.445(0.238)^{*}$ & $-0.980(0.211)^{* * *+\dagger \dagger}$ \\
\hline Adult: $\$ 10$, children: $\$ 3$, family: $\$ 25$ & $-0.110(0.064) *$ & $-0.402(0.246)$ & $-0.821(0.230)^{* * * \dagger \dagger \dagger}$ \\
\hline \multicolumn{4}{|l|}{ b. General entry price } \\
\hline Free & $0.246(0.064) * * *$ & $0.340(0.205)^{*}$ & $1.347(0.252)^{* * * * \dagger \dagger}$ \\
\hline Free, donation appreciated & $0.479(0.068)^{* * *}$ & $1.015(0.260)^{* * * \dagger \dagger}$ & $1.536(0.292) * * * \div \dagger \dagger$ \\
\hline Adult: $\$ 6$, children: Free & $0.188(0.062)^{* * *}$ & $-0.198(0.255)$ & $-0.369(0.226) \div \dagger$ \\
\hline Adult: $\$ 6$, children: $\$ 3$ & $-0.019(0.060)$ & $-0.413(0.242)^{*}$ & $-0.588(0.247)^{* *+4}$ \\
\hline Adult: $\$ 6$, children: $\$ 3$, family: $\$ 15$ & $-0.070(0.060)$ & $-0.070(0.208)$ & $-0.429(0.198)^{* * \dagger}$ \\
\hline Adult: $\$ 10$, children: Free & $-0.235(0.061)^{* * *}$ & $0.037(0.218)$ & $-0.381(0.199)^{*}$ \\
\hline Adult: $\$ 10$, children: $\$ 3$ & $-0.306(0.063)^{* * *}$ & $-0.089(0.248)$ & $-0.851(0.253) * * * \dagger \dagger$ \\
\hline Adult: $\$ 10$, children: $\$ 3$, family: $\$ 25$ & $-0.284(0.063)^{* * *}$ & $-0.622(0.244)^{* *}$ & $-0.266(0.210)$ \\
\hline \multicolumn{4}{|l|}{ c. Staffing } \\
\hline \multicolumn{4}{|l|}{ Staff knowledge } \\
\hline Museum facilities only & $-0.100(0.030)^{* * *}$ & $-0.062(0.100)$ & $-0.574(0.123)^{* * *+\dagger}$ \\
\hline Facilities \& surround area & $0.010(0.026)$ & $-0.048(0.103)$ & $0.113(0.107)$ \\
\hline Facilities and exhibitions & $-0.074(0.029)^{* *}$ & $0.052(0.107)$ & $0.487(0.141)^{* * *+\dagger \dagger}$ \\
\hline Facilities \& expert on exhibitions & $0.163(0.032)^{* * *}$ & $0.058(0.091)$ & $-0.025(0.102) \dagger$ \\
\hline \multicolumn{4}{|l|}{ Location of staff } \\
\hline Located at entrances & $-0.088(0.016)^{* * *}$ & $0.092(0.050)^{*++}+$ & $0.293(0.067)^{* * *+十 \dagger}$ \\
\hline Throughout museum & $0.088(0.016)^{* * *}$ & $-0.092(0.050)^{*}+\dagger \dagger$ & $-0.293(0.067)^{* * *+1}+4$ \\
\hline \multicolumn{4}{|l|}{ Approach to inquiries } \\
\hline Staff approach you & $0.063(0.029)^{* *}$ & $0.069(0.120)$ & $0.174(0.104)^{*}$ \\
\hline You seek/little waiting time & $0.046(0.029)$ & $0.131(0.091)$ & $-0.021(0.100)$ \\
\hline You seek/wait up to 5 minutes & $-0.048(0.029)^{*}$ & $-0.072(0.108)$ & $0.044(0.112)$ \\
\hline \multirow{2}{*}{\multicolumn{4}{|c|}{ d. Tours }} \\
\hline & & & \\
\hline \multicolumn{4}{|l|}{ Size of tour group } \\
\hline Exclusive or small groups & $0.076(0.014)^{* * *}$ & $0.075(0.055)$ & $0.195(0.059) * * * \frac{1}{\dagger}$ \\
\hline Large groups (20-30 people) & $-0.076(0.014)^{* * *}$ & $-0.075(0.055)$ & $-0.195(0.059)$ \\
\hline \multicolumn{4}{|l|}{ Frequency of tours } \\
\hline Depart two times a day & $-0.036(0.014)^{* *}$ & $-0.045(0.048)$ & $0.035(0.054)$ \\
\hline Depart four times a day & $0.036(0.014)^{* *}$ & $0.045(0.048)$ & $-0.035(0.054)$ \\
\hline \multicolumn{4}{|l|}{ Duration of tour } \\
\hline 15 minutes & $-0.105(0.030)^{* * *}$ & $-0.044(0.109)$ & $-0.161(0.113)$ \\
\hline 30 minutes & $-0.005(0.032)$ & $0.013(0.102)$ & $0.020(0.112)$ \\
\hline 1 hour & $0.101(0.030) * * *$ & $0.099(0.111)$ & $-0.530(0.114)^{* * *+\dagger \dagger}$ \\
\hline 2 hours & $0.008(0.029)$ & $-0.068(0.117)$ & $0.670(0.140)^{* * *+\dagger}$ \\
\hline
\end{tabular}


Table 5

Continued

\begin{tabular}{|c|c|c|c|}
\hline & $\begin{array}{l}\text { Class 1: } \\
\text { Life Force }\end{array}$ & $\begin{array}{c}\text { Class 2: } \\
\text { Educated Thinkers }\end{array}$ & $\begin{array}{c}\text { Class } 3: \\
\text { Wealthy At-Homes }\end{array}$ \\
\hline \multicolumn{4}{|l|}{ Tour guide } \\
\hline Volunteers & $-0.002(0.011)^{* * *}$ & $-0.103(0.051)^{* * \dagger}$ & $-0.056(0.047)$ \\
\hline Paid museum staff & $0.002(0.011)^{* * *}$ & $0.103(0.051) * *$ & $0.056(0.047)$ \\
\hline \multicolumn{4}{|l|}{ Exclusivity } \\
\hline See "behind the scenes" & $0.104(0.016)^{* * *}$ & $0.157(0.061)^{* *}$ & $-0.244(0.068)^{* * *}+\dagger \dagger$ \\
\hline See things seen by all visitors & $-0.104(0.016)$ & $-0.157(0.061)^{* *}$ & $0.244(0.068)^{* * *+\dagger \dagger}$ \\
\hline Interactivity & & 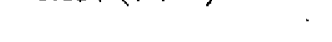 & \\
\hline "Touch" with supervision & $0.176(0.021)^{* * *}$ & $-0.035(0.054) \dagger \dagger \dagger$ & $-0.307(0.071)^{* * * \dagger \dagger \dagger}$ \\
\hline Cannot "touch things" & $-0.176(0.021)^{* * *}$ & $0.035(0.054) \dagger \dagger \dagger$ & $0.307(0.071)^{* * * \dagger \dagger}$ \\
\hline \multicolumn{4}{|l|}{ Tour cost } \\
\hline Free & $0.360(0.037)^{* * *}$ & $0.275(0.111)^{* *}$ & $0.152(0.096)+t$ \\
\hline$\$ 5$ for tour & $0.177(0.031)^{* * *}$ & $0.088(0.101)$ & $-0.255(0.116)^{* *++\dagger}$ \\
\hline$\$ 10$ & $-0.130(0.029)^{* * *}$ & $-0.131(0.104)$ & $-0.250(0.093)^{* * *}$ \\
\hline$\$ 15$ & $-0.407(0.042)^{* * *}$ & $-0.232(0.110)^{* *}$ & $0.353(0.133)^{* * *+1+}$ \\
\hline \multicolumn{4}{|l|}{ e. Interactivity } \\
\hline Education focused & $-0.018(0.018)$ & $1.006(0.133)^{* * * *+中}$ & $-0.153(0.063)^{* *} \dagger \dagger$ \\
\hline Entertainment focused & $0.018(0.018)$ & $-1.006(0.133)^{* * *+4}$ & $0.153(0.063)^{* * \dagger \dagger}$ \\
\hline \multicolumn{4}{|l|}{ f. Children } \\
\hline \multicolumn{4}{|l|}{ Show bag } \\
\hline (Blank: implies no show bag) & $-0.058(0.014)^{* * * *}$ & $-0.053(0.048)$ & $-0.049(0.048)$ \\
\hline Free "show bag" & $0.058(0.014)$ & $0.053(0.048)$ & $0.049(0.048)$ \\
\hline \multicolumn{4}{|l|}{ Supervision } \\
\hline (Blank: No designated area) & $-0.047(0.013)^{* * *}$ & $-0.032(0.047)$ & $-0.188(0.047)^{* * *+1}$ \\
\hline Supervised kids area & $0.047(0.013)$ & $0.032(0.047)$ & $0.188(0.047)^{* * *+\dagger}$ \\
\hline \multicolumn{4}{|l|}{ g. Closing times } \\
\hline \multicolumn{4}{|l|}{ Summer } \\
\hline Closing at $6 \mathrm{pm}$ & $-0.087(0.030)^{* * *}$ & $-0.344(0.122) * *+1 \dagger$ & $0.318(0.114)^{* * * \dagger 十 \dagger}$ \\
\hline $8 \mathrm{pm}$ & $-0.048(0.029)^{*}$ & $0.199(0.120)^{*+\dagger}$ & $0.001(0.500)$ \\
\hline $10 \mathrm{pm}$ & $0.075(0.032)^{* * *}$ & $0.158(0.097)$ & $-0.373(0.111)^{* * * 十 \dagger \dagger}$ \\
\hline Midnight & $0.060(0.029)^{* *}$ & $-0.013(0.108)$ & $0.054(0.110)$ \\
\hline \multicolumn{4}{|l|}{ Winter } \\
\hline Closing at $6 \mathrm{pm}$ & $-0.004(0.027)$ & $-0.244(0.106)^{* *+\dagger}$ & $0.186(0.106)^{* \dagger}$ \\
\hline $8 \mathrm{pm}$ & $-0.015(0.029)$ & $-0.040(0.112)$ & $-0.012(0.095)$ \\
\hline $10 \mathrm{pm}$ & $-0.002(0.027)$ & $0.188(0.104)^{*} \dagger$ & $-0.145(0.104)$ \\
\hline Midnight & $0.022(0.030)$ & $0.096(0.095)$ & $-0.028(0.093)$ \\
\hline \multicolumn{4}{|l|}{ h. Special offers } \\
\hline \multicolumn{4}{|l|}{ Return offer } \\
\hline $20 \%$ off next visit & $-0.092(0.030)^{* * *}$ & $-0.094(0.123)$ & $0.191(0.105)^{*}+\dagger^{\dagger}$ \\
\hline $30 \%$ off next visit & $0.037(0.030)$ & $0.033(0.114)$ & $-0.214(0.095)^{* *+1}$ \\
\hline $50 \%$ off next visit & $0.107(0.031)^{* * *}$ & $0.109(0.116)$ & $-0.394(0.130)^{* * * \frac{1}{\dagger} \dagger \dagger}$ \\
\hline Bring back for free & $-0.052(0.031)^{*}$ & $-0.048(0.107)$ & $0.417(0.117)^{* * * \dagger \dagger \dagger}$ \\
\hline \multicolumn{4}{|l|}{ Discount ( $50 \%$ off shop/entry) ${ }^{\mathrm{a}}$} \\
\hline Museum 1 & $0.063(0.014)^{* * * *}$ & $0.045(0.046)$ & $-0.064(0.043) \dagger \dagger \dagger$ \\
\hline Museum 2 & $0.045(0.013)^{* * *}$ & $-0.009(0.049)$ & $0.100(0.049)^{* *}$ \\
\hline Museum 3 & $0.041(0.013)^{* * *}$ & $-0.096(0.049)^{*} \dagger \dagger \dagger$ & $0.163(0.049) * * * \dagger \dagger$ \\
\hline Museum 4 & $0.053(0.015)^{* * *}$ & $0.080(0.057)$ & $-0.232(0.055)^{* * * \dagger \dagger \dagger}$ \\
\hline Museum 5 & $0.050(0.013)^{* * *}$ & $0.079(0.053)$ & $-0.113(0.051)^{* *+\dagger \dagger}$ \\
\hline Museum 6 & $0.037(0.014)^{* *}$ & $-0.024(0.052)$ & $0.035(0.043)$ \\
\hline \multicolumn{4}{|l|}{ i. Permanent displays } \\
\hline \multicolumn{4}{|l|}{ Frequency displays updated } \\
\hline Every 2 months & $0.342(0.036)^{* * *}$ & $0.075(0.124) \dagger \dagger$ & $0.584(0.118)^{* * *+\dagger}$ \\
\hline Every 6 months & $0.268(0.035)^{* * *}$ & $-0.008(0.118) \dagger \dagger$ & $0.492(0.118)^{* * *+}$ \\
\hline Every year & $0.025(0.028)$ & $0.105(0.095)$ & $-0.474(0.133)^{* * *+\dagger \dagger}$ \\
\hline Rarely & $-0.635(0.052) * * *$ & $-0.172(0.141)+\uparrow \dagger$ & $-0.603(0.116) * * *$ \\
\hline
\end{tabular}

The values are estimated $\beta$ with $\mathrm{SE}$ in parentheses.

${ }^{a}$ The museum discounts were modeled using six two-level attributes. Unlike other tables, values of the base level (no discount) are not explicitly reported, but given by the negative value listed (e.g., matginal utility of museum 1 with no discount is -0.063 ).

Coefficient significant at: $* 0.1, * * 0.5$, and $* * * 0.01$ level; significant from Class 1 at: $\nmid 0.1, \uparrow \nmid 0.5$, and $\dagger \dagger \uparrow 0.01$ level. 
with sensitivity to free entry significantly higher among Wealthy At-Homes, followed by Educated Thinkers (Table 5b). When fees apply, the Life Force class is sensitive to any adult pricing at the $\$ 10$ level, while at the adult price level of $\$ 6$ any fee for children has a strong negative impact. In contrast, Educated Thinkers are largely indifferent to fee options, except for the highest fee family bundled option. Wealthy-At-Homes generally are sensitive to both adult and children fees; family options are a potentially competitive pricing strategy, providing value for money to this class.

\section{Staffing}

Three staff-related attributes were included in the choice scenarios: staff knowledge, their physical location in the museum, and their method of interacting with visitors (Table $5 \mathrm{c}$ ). The largest of the three classes (Life Force) are attracted to staff that have expert knowledge of exhibitions, who are located throughout the museum, and who approach visitors rather than waiting for visitors to ask for assistance. Hence, these visitors appear to be keen to be assisted and directed throughout their museum experience. Educated Thinkers, on the other hand, show little sensitivity to any staffing characteristics, one exception being a marginally significant preference for staff to be located at entrances. In contrast, the Wealthy At-Homes strongly prefer to see staff at the museum entrance and to provide them with general knowledge about the museum facilities and the exhibitions. In other words, they are satisfied to be given a general introduction to the museum's collection and resources, but then perhaps obtain more specific information from place cards, brochures, or, as discussed shortly, guided tours.

\section{Tours}

The DCE varied seven attributes related to museum tours (Table 5d). The Life Force is attracted to frequent tours with limited numbers, longer duration tours (preferably 1 hour) conducted by paid museum staff, options to access things behind the scenes, and opportunities to touch items. They prefer tours to be free, with preferences declining approximately linearly in fees.

There are some interesting differences in the three classes. Members of Wealthy At-Homes prefer tours of 2-hour duration that give access to items accessible by all visitors and which are "look, but don't touch." Wealthy-At-Homes are willing to pay $\$ 15$ for such tours, which may suggest that price signals quality or they hope that higher prices lead to more exclusivity and being with people just like them. There is a strong nonlinear relationship between fees and preferences in this class. These results suggest that it may not be straightforward for museums to set tour fees simply based on length or tour exclusivity.

In comparison with the senses of "touching" (white gloved tours) and "seeing" (behind-thescenes tours), the "listening" aspect (the kind of tour guide) is less important (except in the case of the Educated Thinkers). This is an important insight for museum managers who might contemplate using paid museum staff instead of volunteers in an effort to attract visitors. Results suggest a relatively minor effect in terms of higher visitor numbers.

\section{Interactivity}

The interactivity attribute (Table 5e) applies to two generic types of museum foci: education and entertainment. The Life Force class is indifferent to either type of interactivity. The Educated Thinkers class, on the other hand, prefers education-focused interactivity while the Wealthy AtHomes prefer an entertainment focus.

\section{Children}

Children-related museum attributes (Table 5f) matter to the Life Force class. They prefer free museum show bags (with mementos and other goodies) and the ability to put children in a supervised area. The Wealthy At-Homes class has even stronger supervision preferences. Educated Thinkers are indifferent to child-relevant attributes.

\section{Closing Time}

Significant closing time effects (Table $5 \mathrm{~g}$ ) are mainly associated with summer. The Life Force class prefers museums that open until very late, including midnight closing, which implies that they see a museum visit as an alternative to other 
after-hours leisure activities like theatrrs, restaurants, or bars. Educated Thinkers also prefer museums that are open until after 6:00 pm in summer, and prefer an 8:00 pm closing time. Wealthy AtHomes do not respond to closing times beyond 6 : $00 \mathrm{pm}$.

\section{Special Offers}

The DCE varied two types of special offers (Table 5h): inducements for visitors to return to the museum and cross-promotional offers to visit other museums. The DCE used specific named museums (not identified here to honor the nondisclosure agreement with the collaborating partner museums). The Life Force class responds positively to all cross-promotional inducements, whereas Educated Thinkers are indifferent to all offers. Wealthy At-Homes are more selective, responding both positively and negatively to the offers. We note in passing that difference in geographic locations and associated travel costs of cross-visitation likely explain some of these results.

The Life Force class responds positively to a discounted return visit, whereas the Educated Thinkers are indifferent to this offer. Discounting more than $20 \%$ has a negative effect on preferences of Wealthy At-Homes, but this class responds positively to the option to return with a family member or friend at a later time.

\section{Permanent Displays}

The final attribute for a museum (re)visit was the effect of temporal changes on the museum experience (Table 5i). Visitors may delay returning until they think that the permanent exhibits and displays change sufficiently, which typically is associated with rotating collections and permanent displays. The Life Force class responds negatively to infrequent changes in permanent displays and positively to more frequent rotations. Wealthy AtHomes also respond positively to shorter rotations (less than 6 months); they dislike annual updating and rarely changing offerings. In contrast, Educated Thinkers are indifferent to updating.

\section{Summary and Conclusions}

The objective of this article was to introduce and describe a new way to understand and quan- tify the value of numerous tangible and intangible factors that might be used to affect visitor experiences and visitation choices. A second objective was to show that one can simultaneously account for differences in a sample of respondents (in this case, museum visitors) in terms of their underlying preferences and choice consistency.

To achieve our objectives, we designed and implemented an online DCE that asked respondents to choose their preferred museum offering, where the offerings were described by 26 attributes whose levels were varied by an underlying experimental design. Attributes and levels were informed by qualitative research, and a best-worst scaling study was used to determine the relative importance of 64 attributes. The list of 64 attributes was further refined in consultation with six Australian museums who collaborated in the research process.

The impacts of changes in attributes of museum offerings and choices were estimated using a recent development in DCMs called a SALCM. This new approach allowed us to identify two latent scale classes that differed in choice consistency. Previous approaches to latent class modeling have focused on accounting for differences in preference only. However, because we have applied a model that accounts for additional differences in choice consistency, the confounding between error variability and parameter estimates has been avoided. In turn, our conclusions and interpretation of any preference classes are free from any bias relating to ignoring differences in variance. With this in mind, the model simultaneously identified and estimated parameters for three latent preference classes, and estimated relationships between several sociodemographic covariates, activities and interests in exhibitions, and class membership. Three underlying classes were profiled and described as being the Life Force of the museum visitors (around two thirds of visitors), Educated Thinkers, and Wealthy At-Homes.

Our results suggest many ways that museum managers can attract more visitors by changing offerings associated with several attributes/levels. The model allows one to predict the impact that small or large changes (within the ranges of the levels studied) will have both in terms of general demand and among each segment identified. Such 
predictions can be made over a number of different areas of operation (e.g., pricing, tours) and the impact can be compared in relative terms. This is because the research method embedded the implicit trade-offs that respondents made between various attributes in the context of the discrete choice scenarios.

Not surprisingly, all visitors are attracted to museums with special exhibitions that are competitively priced and rated as "not to be missed." Price sensitivity also applies to general entry prices, and confirms that museums that offer free entry or entry "by donation" are the most preferred. Tours are preferable if smaller in number, lengthier, and conducted by paid museum staff, with some indifference to tour attributes (e.g., among Educated Thinkers). Museums should cater for children, with some classes responding strongly and positively to providing supervised child areas. Most visitors (Educated Thinkers an exception) prefer museums that change often, offering new experiences and some level of updating to permanent displays.

Museums should consider the underlying preference classes in making strategic decisions about segmentation and targeting. For example, the classes differ in preferences for types of tours including the aspects of what they will see and what it costs. Educated Thinkers see museums as educational opportunities, but Wealthy At-Homes prefer museums that offer entertaining experiences. The Life Force class is indifferent to types of interactivity, which may be true indifference or additional preference heterogeneity not accounted for in this class (Hutchinson et al., 2000). Another class difference is associated with extended opening hours; most prefer longer opening hours in summer, but are indifferent towards longer winter hours. Finally, incentives to return visits were valued by the Life Force class, but have little effect on Educated Thinkers, with the latter class also unaffected by cross-museum promotional offers.

Our findings suggest many different ways that a museum experience can be enjoyed. An experience comprises various attributes that can be changed by museum managers to align to the preferences of their audiences. However, to make good decisions about the offerings, and adopt better positions, museum managers need to be aware of audience heterogeneity. The modeling approach discussed in this article provides a way to identify and target various visitor segments.

\section{Acknowledgments}

This research was supported by an Australian Research Council Linkage Project Grant. The authors gratefully acknowledge the contributions made by six major Australian museums that participated. The authors would also like to thank three anonymous referees for their useful suggestions.

\section{References}

Adamowicz, W., Bunch, D., Cameron, T., Dellaert, B., Hanneman, M., Keane, M., Louviere, J., Meyer, R., Steenburgh, T., \& Swait, J. (2008). Behavioral frontiers in choice modeling. Marketing Letters, 19(3-4), 215228.

Andrews, R. L., Ainslie, A., \& Currim, I. S. (2002). An empirical comparison of logit choice models with discrete versus continuous representations of heterogeneity. Journal of Marketing Research, 39, 479-487.

Apostolakis, A., \& Jaffry, S. (2005). A choice modeling application for Greek heritage attractions. Journal of Travel Research, 43, 309-318.

Auger, P., Burke, P., Devinney, T., \& Louviere, J.J. (2003). What will consumers pay for social product features? Journal of Business Ethics, 42(3), 281-304.

Biehal, G., \& Chakravarti, D. (1989). The effects of concurrent verbalization on choice processing. Journal of Marketing Research, 26(2), 84--96.

Bitgood, S. (2006). An analysis of visitor circulation: Movement patterns and the general value principle. $C_{u-}$ rator, 49(4), 463-475.

Boorsma, M. (2006). A strategic logic for arts marketing. International Journal of Cultural Policy, 12(1), 73-92.

Boxall, P., Englin, J., \& Adamowicz, W. L. (2003). Valuing aboriginal attefacts: A combined revealed-stated preference approach. Journal of Environmental Economics and Management, 45, 213-30.

Burke, P. F., \& Reitzig, M. (2007). Measuring patent assessment quality-Analyzing the degree and kind of (in)consistency in patent offices" decision making. Research Policy, 36(9), 1404-30.

Burton, C. (2003). Scoping the challenge: Entrepreneurial arts management in times of uncertainty. Journal of Arts Management, Law and Society, 3(3), 185-195.

Burton, C., \& Scott, C. (2003). Museums: Challenges for the 21 st century. International Journal of Arts Management, 5(2), 56-68.

Burton, C., Louviere, J., \& Young, L. (2008). Retaining the visitor, enhancing the experience: Identifying attributes of choice in repeat museum visitation. International 
Journal of Nonprofit and Voluntary Sector Marketing $14(1), 21-34$.

Cahill, D. J. (1996). Pioneer advantage: Is it real? Does it matter? Marketing Intelligence \& Planning, 14(4), 5-8.

Caldwell, N., \& Coshall, J. (2003). Tourists' preference structures for London's Tate Modern Gallery: The implications for strategic marketing. Joumal of Travel \& Tourism Marketing, 14(2), 23-45.

Carson, R. T., \& Groves, T. (2007). Incentive and informational properties of preference questions. Envirommental and Resource Economics, 37, 181-210.

Clopton, S., Stoddard, J. E., \& Dave, D. (2006). Event preferences among arts patrons: Implications for market segmentation and arts management. International Journal of Arts Management, 9(1), 48 $\sim 77$.

Cohen, S., \& Orme, B. (2004). What's your preferences? Asking survey respondents about their preferences creates new scaling decisions. Marketing Research, 16(2), 32-37.

Cohen, S., \& Neira, L. (2003). Measuring preferences for product benefits across countries: Overcoming scale usage bias with maximum difference scaling. Paper presented at the Latin American Conference of the European Society for Opinion and Marketing Research, Punta del Este, Unuguay.

Colombino, U., \& Nese, A. (2009). Preference heterogeneity in relation to museum services. Tourism Economics, I5(2), 381-395.

Debenedetti, S. (2003). Investigating the role of companions in the art museum experience. International Journal of Arts Management, 5(3), 52-63.

Dolnicar, S. (2004). Beyond "commonsense segmentation: " A systematics of segmentation approaches in tourism. Journal of Travel Research, 42(3), 244-250.

Falk, J. H. (2006). An identity-centred approach to understanding museum learning. Curator, 49(2), 151-166.

Fiebig, D., Keane, M., Louviere, J. J., \& Wasi, N. (in press). The generalized multinomial logit model. Marketing Science.

Goulding, C. (2000). The museum environment and the visitor experience. European Journal of Marketing, $34(3-4), 261-272$.

Gupta, S, \& Chintagunta, P. K. (1994). On using demographic variables to determine segment membership in logit mixture models. Journal of Marketing Research, $31(1), 128-36$.

Hensher, D. A., \& Greene, W. (2002). Specification and estimation of the nested logit model: Alternative normalisations. Transportation Research B-Methodological, 36(1), 1-17.

Holden (2003). Capturing cultural value: How culture has become a tool of government. London: Demos.

Hui, C. H., \& Triandis, H. C. (1989). Effects of culture and response format on extreme response style. Journal of Cross-Cultural Psychology, 20(3), 296-309.

Hutchinson, J. W., Kamakura, W. A., \& Lynch, Jr, J, G. (2000). Unobserved heterogeneity as an alternative ex- planation for "reversal" effects in behavioral research. Journal of Consumer Research, 27(3), 324-44.

Huybers, T., \& Bennett, J. (2000). Impact of the environment on holiday destination choices of prospective UK tourists: Implications for Tropical North Queensland. Tourism Economics, 6(1), 21-46.

Islam, .T., Louviere, J. J, \& Burke, P. (2007). Modeling the effects of including/excluding attributes in choice experiments on systematic and random components. International Journal of Research in Marketing, 24, 289 300.

Jaccard, J., Brinberg, D., \& Lee, J. A. (1986). Assessing attribute importance: A comparison of six methods. Journal of Consumer Research, 12(4), 463-468.

Johnson, P., \& Thomas, B. (1998). The economics of museums: A research perspective. Journal of Cultural Eco. nomics, $22,75-85$.

Joy, A., \& Sherry, J. F. (2003). Speaking of art as embodied imagination: A multisensory approach to understanding aesthetic experience. Journal of Consumer Research 30(2), 59-82.

Kamakura, W. A., \& Russell, G. J. (1989). A probabilistic choice model for market segmentation and elasticity structuring. Journal of Marketing Research, 26, 379-90.

Kelly, L. (2004). Evaluation, research and communities of practice: Program evaluation in museums. Archival Science, 4, 45-69.

Kirchberg, V. (1996). Museum visitors and non-visitors in Germany: A representative survey. Poetics, 24, 239258.

Lancaster, K. (1966). A new approach to consumer theory. Journal of Political Economy, 74(2), 132-157.

Lee, H-K. (2005). Rethinking arts marketing in a changing cultural policy context. International Journal of Nonprofit and Voluntary Sector Marketing, 10, 151-164.

Lindberg, K., Dellaert, B., \& Rassing, C. R. (1999). Resident trade-offs-A choice modeling approach. Annals of Tourism Research, 26(3), 554-569.

Louviere, J. J. (1988). Analyzing decision making--metric conjoint analysis. Newbury Park, CA: Sage.

Louviere, J. J. (2001). What if consumer experiments impact variances as well as means? Response variability as a behavioral phenomenon. Journal of Consumer Research, 28(3), 506-11.

Louviere, J. J., Hensher, D. A., \& Swait, J, D. (2000). Stated choice methods. Cambridge: Cambridge University Press.

Louviere, J. J., \& Islam, T. (2008). A comparison of impor. tance weights and willingness-to-pay measures derived from choice-based conjoint, constant sum scales and best-worst scaling. Joumal of Business Research, 61(9), 903-911.

Louviere, J. J., Street, D., Burgess, L., Wasi, N., Islam, T., \& Marley, A. A. J. (2008). Modeling the choices of individual decision-makers by combining efficient choice experiment designs with extra preference information. The Journal of Choice Modeling, 1(1), 128163. 
Louviere, J. J., \& Swait, J. (2010). Commentary: Discussion of 'Alleviating the constant stochastic variance assumption in decision research: Theory, measurement and experimental test.' Marketing Science, 29(1), $18-22$.

Maddison, D., \& Foster, T. (2003). Valuing congestion costs in the British Museum. Oxford Economic Papers, $55,173-90$.

Magidson, J., \& Vermunt, J. (2005). Technical guide to Latent Gold Software 4.5. Statistical Innovations.

Manski, C. (1977). The structure of random utility models. Theory and Decision, 8, 229-54.

Marley, A., \& Louviere, J. J. (2005). Some probabilistic models of best, worst and best-worst choices. Journal of Mathematical Psychology, 19, 464-480.

Mazzanti, M. (2003). Valuing cultural heritage in a multiattribute framework microeconomic perspectives and policy implications. Journal of Socio-Economics, 32, 549-569.

McFadden, D. (1974). Conditional logit analysis of qualitative choice behavior. In P. Zarembka (Ed.), Frontiers in econometrics (pp. 105-142). New York: Academic Press.

Mitchell, R. C., \& Carson, R. T. (1989). Using surveys to yalue public goods: The contingent valuation method. Washington, DC: Resources for the Future.

Morley, C. L. (1994). Experimental destination choice analysis. Annals of Tourism Research, 21(4), 780-791.

Mroz, A. T., \& Zayats, V. Y. (2008). Arbitrarily normalized coefficients, information sets, and false reports of 'biases' in binary outcome models. Review of Economics and Statistics, 90(3), 406-413.

Noonan, D. (2003). Contingent valuation and cultural resources: A meta-analytic review of the literature. Journal of Cultural Economics, 27, 159-176.

Oh, C-O., Ditton, R., Gentner, B., \& Ricchers, R. (2005). A stated preference choice approach to understanding angler preferences for management options. Human Dimensions of Wildlife, 10(3), 173-86.

Ready, R., Epp, D., \& Delavan, W. (2005). A comparison of revealed, stated, and actual behavior in response to a change in fishing quality. Human Dimensions of Wildlife, $10(1), 39-52$.

Rolfe, J., \& Windle, J. (2003). Valuing the protection of aboriginal cultural heritage sites. Economic Record, 79 , s85-s95.

Salisbury, L., \& Feinberg, F. (2010). Alleviating the con- stant stochastic variance assumption in decision research: Theory, measurement and experimental test, Marketing Science, 29(1), 1-17.

Santagata, W., \& Signorello, G. (2000). Contingent valuation of a cultural public good and policy design: The case of "Napoli Musei Aperti." Journal of Cultural Economics, 24, 181-204.

Slater, A. (2007). "Escaping to the gallery:" Understanding the motivations of visitors to galleries. International Journal of Nonprofit Voluntary Sector Marketing, 12, $149-162$.

Sheth, J. N., Newman, B. I., \& Gross, B. L. (1991). Why we buy what we buy: A theory of consumption values. Journal of Business Research, 22(2), 159-70.

Street, D., \& Burgess, L. (2007). The construction of optimal stated choice experintents: Theory and methods. Hoboken, NJ: John Wiley and Sons.

Swait, J., \& Louviere, J. J. (1993). The role of the scale parameter in the estimation and comparison of multinomial logit models. Journal of Marketing Research. $30(3), 305-14$.

Throsby, D. (2001). Economics and culture. Cambridge: Cambridge University Press.

Thyne, M. (2000). The importance of values research for nonprofit organisations: The motivation-based values of museum visitors. International Journal of Nonprofit and Voluntary Sector Marketing, 6(2), 116-130.

Thurstone, L. L. (1927). A law of comparative judgment. Psychological Review, 34, 273-86.

Train, K. (2003). Discrete choice methods with simulation. Cambridge: Cambridge University Press.

Verma, R., Louviere, J., \& Burke, P. (2006). Using a market-utility-based approach to designing public services: A case illustration from United States Forest Service. Journal of Operations Management, 24(4), 407-16.

Wedel, M., \& Kamakura, W. A. (1998). Marketing segmentation: Conceptual and methodological foundations. Boston: Kluwer.

Weil, S. E. (2002). Making museums matter. Washington, DC: Smithsonian Institute Press.

Wiggins, J. (2004). Motivation, ability and opportunity to participate: A reconceptualization of the RAND model of audience development. International Journal of Arts Management, $7(1), 22-33$.

Yatchew, A., \& Griliches, Z. (1985). Specification error in probit models. The Review of Economics and Statistics, $67(1), 134-139$. 